\title{
D-Amino-Acid Oxidase Inhibition Increases D-Serine Plasma Levels in Mouse But not in Monkey or Dog
}

\author{
Camilo Rojas',2, Jesse Alt', Nancy A Ator ${ }^{3}$, Ajit G Thomas', Ying Wu', Niyada Hin', Krystyna Wozniak', \\ Dana Ferraris', Rana Rais ${ }^{1,4}$, Takashi Tsukamoto ${ }^{1,4}$ and Barbara S Slusher ${ }^{*, 1,3,4,5}$ \\ Johns Hopkins Drug Discovery, Baltimore, MD, USA; ${ }^{2}$ Department of Molecular and Comparative Pathobiology, Baltimore, MD, USA; \\ ${ }^{3}$ Department of Psychiatry and Behavioral Sciences, Baltimore, MD, USA; ${ }^{4}$ Department of Neurology, Baltimore, MD, USA; ${ }^{5}$ Department of \\ Neuroscience, Johns Hopkins University, Baltimore, MD, USA
}

\begin{abstract}
D-serine has been shown to improve positive, negative, and cognitive symptoms when used as add-on therapy for the treatment of schizophrenia. However, D-serine has to be administered at high doses to observe clinical effects. This is thought to be due to D-serine undergoing oxidation by D-amino-acid oxidase (DAAO) before it reaches the brain. Consequently, co-administration of D-serine with a DAAO inhibitor could be a way to lower the D-serine dose required to treat schizophrenia. Early studies in rodents to evaluate this hypothesis showed that concomitant administration of structurally distinct DAAO inhibitors with D-serine enhanced plasma and brain $\mathrm{D}$-serine levels in rodents compared with administration of D-serine alone. In the present work we used three potent DAAO inhibitors and confirmed previous results in mice. In a follow-up effort, we evaluated plasma D-serine levels in monkeys after oral administration of $\mathrm{D}$-serine in the presence or absence of these DAAO inhibitors. Even though the compounds reached steady state plasma concentrations exceeding their $K_{i}$ values by $>60$-fold, plasma D-serine levels remained the same as those in the absence of DAAO inhibitors. Similar results were obtained with dogs. In summary, in contrast to rodents, DAAO inhibition in monkeys and dogs did not influence the exposure to exogenously administered D-serine. Results could be due to differences in D-serine metabolism and/or clearance mechanisms and suggest that the role of DAAO in the metabolism of D-serine is different across species. These data provide caution regarding the utility of DAAO inhibition for patients with schizophrenia.

Neuropsychopharmacology (2016) 41, 1610-1619; doi:10.1038/npp.2015.319; published online 18 November 2015
\end{abstract}

\section{INTRODUCTION}

Antagonists of the $N$-methyl D-aspartate (NMDA) receptor such as phencyclidine and ketamine induce negative symptoms and cognitive deficits typical of schizophrenia in healthy volunteers (Malhotra et al, 1996) and exacerbate psychosis in patients diagnosed with the disease (Malhotra et al, 1997). These findings have led to the hypothesis that hypofunction of the NMDA receptor may contribute to the disorder (Coyle, 2006; Javitt et al, 2001) and that potentiation of receptor function may alleviate some of the symptoms of schizophrenia (Yang and Svensson, 2008). As excessive stimulation of the NMDA receptor glutamate-binding site may cause excitotoxic damage to neurons, drug discovery efforts have focused on increasing glutamatergic neurotransmission by activating the glycine modulatory site on NMDA receptors. The use of $\mathrm{D}$-serine to potentiate NMDA receptormediated neurotransmission has been particularly attractive because it is a more potent allosteric activator than glycine

* Correspondence: Professor BS Slusher, Department of Neurology, Johns Hopkins University, 855 North Wolfe, Suite 277, Baltimore, MD 21205, USA, Tel: +1 410 614 0662, Fax: +1 410 6140659, E-mail: bslusher@jhmi.edu

Received 12 August 2015; revised 9 October 2015; accepted 10 October 2015; accepted article preview online 16 October 2015
(Mothet et al, 2000), it is more permeable than glycine to the blood-brain barrier (Oldendorf, 1971) and it is not known to affect other neurotransmitter systems. There have been several small clinical studies ranging from 20 to 195 patients where D-serine has been tested in combination with other antipsychotics for the treatment of schizophrenia (Heresco-Levy et al, 2005; Kantrowitz et al, 2010; Lane et al, 2005, 2010; Tsai et al, 1998, 1999; Weiser et al, 2012). Patients who have received D-serine have shown improvement in some clinical studies (Heresco-Levy et al, 2005; Kantrowitz et al, 2010; Tsai et al, 1998), whereas in others there was no effect (Lane et al, 2005, 2010; Tsai et al, 1999; Weiser et al, 2012). Only one study examined D-serine dose response $(30-120 \mathrm{mg} / \mathrm{kg} / \mathrm{day})$ and the most improvement was seen at doses $\geqslant 60 \mathrm{mg} / \mathrm{kg} /$ day (Kantrowitz et al, 2010). The rest of the studies only tested lower doses $(30 \mathrm{mg} / \mathrm{kg} / \mathrm{day}$ or $2 \mathrm{~g} /$ day) (Heresco-Levy et al, 2005; Lane et al, 2005, 2010; Tsai et al, 1998, 1999; Weiser et al, 2012).

The need for large doses to observe efficacy is thought to be due to D-serine undergoing extensive oxidation by D-amino-acid oxidase (DAAO) (Sacchi et al, 2008). DAAO is a flavoprotein that has been shown to oxidize a wide variety of substrates including D-alanine, D-serine, D-proline, D-DOPA, and D-kynurenine (Dixon and Kleppe, 1965; Iwasa et al, 2011; Kawazoe et al, 2007a; Ogaya et al, 
<smiles>N[C@@H](CO)C(=O)O</smiles>
D-serine

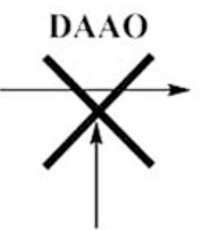

DAAO inhibitor<smiles>O=C(O)C(=O)CO</smiles>

$+\mathrm{H}_{2} \mathrm{O}_{2}+\mathrm{NH}_{3}$ 
standardized synthetic diet (Harlan Teklab). Room temperature and humidity were maintained at $20^{\circ} \mathrm{C}$ and $55 \pm 10 \%$, respectively. Artificial lighting was provided in 12-hour light/ dark cycles (light 7 AM-7 PM). Terminal blood samples were performed by cardiac puncture following euthanasia by $\mathrm{CO}_{2}$ inhalation. Care and use of the mice was consistent with Public Health Service Policy on the Care and Use of Laboratory Animals (Department of Health and Human Services, National Institutes of Health, Office of laboratory Animal Welfare).

Oral D-serine \pm single oral administration of $D A A O$ inhibitors. Mice were dosed orally with D-serine $(30 \mathrm{mg} / \mathrm{kg}) \pm$ the DAAO inhibitors CBIO, JHU 1057 or JHU 1377 (30 mg/kg). Compounds were dissolved in $\mathrm{H}_{2} \mathrm{O} /$ saline (80/20\% by volume) containing $40 \mathrm{mg}$ glucose/ml. DAAO inhibitors were dosed immediately following the D-serine dose. Unless otherwise noted, animals $(n=3$ at each time point) were sacrificed at $0.25,0.5,1,2,3$ and $6 \mathrm{~h}$ after $\mathrm{D}$-serine dosing and blood was collected by cardiac puncture. Blood samples were centrifuged at $3000 \times \mathrm{g}$ for $10 \mathrm{~min}$, and the resulting plasma was stored at $-80^{\circ} \mathrm{C}$ until time of analysis.

Oral D-serine \pm chronic intravenous infusion of DAAO inhibitor. CD1 mice (6-8 weeks old, Harlan) were anesthetized with an i.p. injection of $0.1-0.15 \mathrm{ml}$ of $10 \%$ chloral hydrate dissolved in $0.9 \%$ saline. Alzet minipumps (model 2001D) were primed by incubation in saline at $37^{\circ} \mathrm{C}$ for $8 \mathrm{~h}$ and then inserted subcutaneously with a catheter (part: 0007701) placed into the jugular vein. The pumps delivered $1 \mathrm{mg} / \mathrm{kg} / \mathrm{h}$ of $\mathrm{JHU} 1057$ for the duration of the experiment. D-serine $(30 \mathrm{mg} / \mathrm{kg})$ was administered orally 30 min following beginning of IV infusion. Mice were then killed at $0.25,0.5,1,3,5$, and $18 \mathrm{~h}$ after D-serine administration. Blood was collected and treated to generate plasma as described above.

\section{Baboon Pharmacokinetic Studies}

Adult male baboons (Papio hamadryas of anubis subtype, olive baboon, weighing $26-30 \mathrm{~kg}$ ) were housed individually in stainless-steel cages in a temperature- and humiditycontrolled facility with constant access to water and an 11-h artificial light/dark cycle (light 6 AM-PM) although there was natural light through windows. The baboons were fed generous amounts of Old World Monkey chow and at least one piece of fresh fruit daily at approximately the same time of the morning. They could see and hear each other as well as other baboons in the same housing area. The baboons each had been surgically implanted with chronically indwelling jugular or femoral venous catheter that was protected via a custom-constructed tether/harness system (Lukas et al, 1982). A slow continuous infusion of lightly heparinized $0.9 \%$ saline $(\sim 150 \mathrm{ml}$ in $24 \mathrm{~h})$ maintained catheter patency. Both baboons had previous experience in a study of intravenous drug self-administration. Care and use of the baboons was consistent with both Public Health Service Policy (cited above) as well as the US Animal Welfare Act (9 CFR Parts 1, 2, 3).
Oral D-serine. Baboons were habituated across days to drink $60 \mathrm{ml}$ of an orange-flavored solution (Tang) that was made increasingly bitter with the addition of quinine sulfate using a well-established training procedure that does not require restriction of access to water; drinking was followed immediately by $40 \mathrm{ml}$ of unadulterated orange drink (Ator, 2000). To test the likelihood that drug solution would be consumed on the day of the experiment, they were provided the planned dose of $\mathrm{D}$-serine in the orange drink without quinine, which they consumed rapidly. Thus, a week later, on the day of the experiment, they voluntarily drank the $\mathrm{D}$-serine dose $(30 \mathrm{mg} / \mathrm{kg})$ within $5 \mathrm{~min}$. The baboons were sedated with Telazol (tiletamine+zolazepam) i.m. (preceded by atropine sulfate to control secretions) so that blood $(3 \mathrm{ml})$ could be collected from a cephalic or saphenous vein at $0.25,0.5,1,2,4,6,8$, and $24 \mathrm{~h}$ after the $\mathrm{D}$-serine dose was consumed. Blood was centrifuged at $3000 \mathrm{rpm}$ for $10 \mathrm{~min}$ to separate plasma from red cells, and plasma was stored at $80^{\circ} \mathrm{C}$ until time of analysis.

Oral D-serine \pm chronic intravenous DAAO inhibitors. CBIO, JHU 1057 and 1377 were dissolved in 5\% dextrose solution and filter sterilized $(0.22 \mu \mathrm{m})$ for i.v. delivery. Baboons were dosed with the DAAO inhibitor $(0.5 \mathrm{mg} / \mathrm{kg} / \mathrm{h})$ by constant i.v. infusion for $24 \mathrm{~h}$ in place of the heparinized saline drip mentioned above. D-serine (30 mg/kg, p.o.) was consumed voluntarily $15 \mathrm{~min}$ after initiation of the i.v. infusion, and blood samples were collected at the same intervals as above.

\section{Beagle Dog Pharmacokinetic Studies}

Dog studies were carried out by Ricerca Biosciences, LLC (Concord, $\mathrm{OH}$ ). Two laboratory-bred and experimentally non-naive male beagle dogs (12-16 months of age weighing 9-10 kg) were used. Care and use of the dogs was consistent with both Public Health Service Policy (cited above) as well as the US Animal Welfare Act (9 CFR Parts 1, 2, 3). Dogs were implanted with indwelling venous catheters. Certified Canine Diet was provided daily in amounts appropriate for the size and age of the dogs. Tap water was available ad libitum.

Oral D-serine. $\quad$ D-serine $(10 \mathrm{mg} / \mathrm{kg}$ p.o. dissolved in distilled water containing $0.5 \%$ methylcellulose) was given and blood samples ( $1 \mathrm{ml} / \mathrm{sample})$ were collected via venipuncture of the cephalic vein at $0.25,0.5,1,2,4,6,8$, and $24 \mathrm{~h}$ after dosing. Blood samples were collected and processed as above.

Oral D-serine \pm chronic intravenous DAAO inhibitor. D-serine $(10 \mathrm{mg} / \mathrm{kg}$, p.o.) was given $2 \mathrm{~h}$ before initiation of the intravenous JHU 1057 (10 mg / kg bolus followed by continuous i.v. infusion of $10 \mathrm{mg} / \mathrm{kg} / \mathrm{h}$ for $6 \mathrm{~h}$ ). JHU 1057 was dissolved in sterile water $(80 \%)$ plus saline containing $50 \mathrm{mg} / \mathrm{ml}$ dextrose (20\%). JHU 1057 was given $2 \mathrm{~h}$ after D-serine administration after the absorption phase but at a time when D-serine concentration was expected to be high. Blood samples were collected at $0.25,0.5,1,2,4,6$, and $8 \mathrm{~h}$ after dosing with $\mathrm{D}$-serine and processed as detailed above. 


\section{Determination of $\mathrm{D}$-serine in Plasma}

D-serine analysis was based on a previously published procedure involving derivatization with Marfey's reagent (Berna and Ackermann, 2007).

\section{Determination of DAAO Inhibitors in Plasma}

Mouse, baboon, or dog plasma was spiked with CBIO, JHU 1057, or JHU 1377 at 100, 31.6, 10, 3.2, 1, 0.3, 0.1, 0.03, 0.01, $0 \mu \mathrm{M}$ by serial dilution. Samples $(50 \mu \mathrm{l})$ of the calibration standard or test samples were transferred into low-retention microcentrifuge tubes for extraction. Sample preparation involved a single liquid extraction with $500 \mu$ l acetonitrile spiked with $1 \mu \mathrm{M}$ CBIO (for JHU 1057 and JHU 1377 analysis) or $0.5 \mu \mathrm{M}$ losartan (for $\mathrm{CBIO}$ analysis) as ISTD. Extracts were centrifuged at $16000 \mathrm{~g}$ for $5 \mathrm{~min}$ at $4{ }^{\circ} \mathrm{C}$. Supernatants $(450 \mu \mathrm{l})$ were transferred to new low-retention microcentrifuge tubes and dried under vacuum at $45^{\circ} \mathrm{C}$ for $45 \mathrm{~min}$. Samples were reconstituted in $50 \mu \mathrm{l}$ of $30 \%$ acetonitrile and centrifuged at $16000 \mathrm{~g}$ for $5 \mathrm{~min}$ at $4{ }^{\circ} \mathrm{C}$. Supernatants were then transferred into a 96-well plate. For JHU 1057 and 1377, a volume of $10 \mu \mathrm{l}$ was injected onto an Agilent 1290 UPLC system with an Agilent Zorbax $1 \times 150 \mathrm{~mm}$ C18 column using a gradient run of $10 / 90-100 / 0$ acetonitrile/water $+0.1 \%$ formic acid at $0.2 \mathrm{ml} / \mathrm{min}$ over $3.5 \mathrm{~min}$ and detected on an Agilent 6520 QTOF mass spectrometer. For CBIO, a volume of $10 \mu \mathrm{l}$ was injected onto an Agilent 1290 UPLC system with an Agilent Zorbax $2.1 \times 100 \mathrm{~mm} \mathrm{C18}$ column using a gradient run of 30/70-90/10 acetonitrile/water $+0.1 \%$ formic acid at $0.3 \mathrm{ml} / \mathrm{min}$ over $4 \mathrm{~min}$ and detected on an Agilent 6520 QTOF mass spectrometer. The lower limit of quantitation for each analyte was about $0.03 \mu \mathrm{M}$ of DAAO in plasma. Standards within the quantifiable range were used to generate a standard curve.

\section{Pharmacokinetics Parameter Calculations}

Determinations of AUC using the trapezoidal approximation and terminal half-lives for DAAO inhibitors were performed with the pharmacokinetics (PK) Functions for Microsoft Excel macro (Joel I Usansky, PhD, Atul Desai, MS, and Diane Tang-Liu, PhD; Department of Pharmacokinetics and Drug Metabolism Allergan, Irvine, CA 92606, USA). Statistical evaluation of differences between AUC values $(\mathrm{nmolh} / \mathrm{ml})$ in mouse studies was carried out using the Bailer method employing the $Z$ observed value $\left(Z_{\text {obs }}\right)$; $Z_{\text {obs }}>1.96$ was considered significant (Bailer, 1988).

\section{Plasma Protein Binding}

Plasma protein binding (PPB) was carried out by equilibrium dialysis as previously described (Acharya et al, 2006).

\section{RESULTS}

\section{Orally Administered DAAO Inhibitors Increased D-serine Plasma Exposure in Mice}

DAAO inhibitors CBIO, JHU 1057, and JHU 1377 with $K_{\mathrm{i}}$ values of 20,30 , and $40 \mathrm{nM}$, respectively (Figure $1 \mathrm{~b}-\mathrm{d}$ ) were utilized to evaluate whether DAAO inhibition could increase $\mathrm{D}$-serine exposure in mice. D-serine $(30 \mathrm{mg} / \mathrm{kg}$ $\mathrm{PO}) \pm$ DAAO inhibitor (30 or $100 \mathrm{mg} / \mathrm{kg}$ PO) was administered concomitantly and plasma samples were collected at various time points after administration. D-serine and DAAO inhibitor concentrations in plasma were determined by LC-MS. In each case, administration of DAAO inhibitor with D-serine exhibited a statistically significant increase in plasma D-serine exposure compared with administration of D-serine alone (Figure 2a, c, e and g). Although the effects of the DAAO inhibitors on D-serine exposure were statistically significant in each case $(Z c r i t>1.96)$, the effects were short lived. This was likely due to DAAO inhibitors clearing rapidly from plasma with terminal half-lives of $2.3,1.8$, and $1.9 \mathrm{~h}$ for CBIO, JHU 1057, and JHU 1377, respectively (Figure 2b, d, f). Given the short DAAO inhibitor plasma exposure following single oral administration, a continuous i.v. infusion-dosing strategy was subsequently used with JHU 1057 to fully evaluate the effect of continuous DAAO inhibition on $\mathrm{D}$-serine in mice.

\section{Infusion of DAAO Inhibitor Increased D-serine Plasma Exposure in Mice}

To determine whether continuous DAAO inhibitor exposure would result in sustained D-serine levels, D-serine was given as single dose (30 mg/kg PO) $30 \mathrm{~min}$ after initiating a continuous IV infusion of JHU 1057 ( $1 \mathrm{mg} / \mathrm{kg} / \mathrm{h})$. The IV infusion dose was chosen because higher doses $(3 \mathrm{mg} / \mathrm{kg} / \mathrm{h}$ or higher) caused mild sedation; in contrast, $1 \mathrm{ml} / \mathrm{kg} / \mathrm{h}$ caused no overt behavioral effects. IV infusion of JHU 1057 resulted in sustained levels of plasma D-serine (Figure 3a). D-serine exposure $\left(\mathrm{AUC}_{0-3 \mathrm{~h}}\right)$ was lowest when using $\mathrm{D}$-serine alone, intermediate when using $\mathrm{D}$-serine plus single dose of JHU 1057 (100 mg/kg PO) and highest when using D-serine+chronic IV infusion of JHU 1057 $(1 \mathrm{mg} / \mathrm{kg} / \mathrm{h})$ (Figure $3 \mathrm{~b})$. The results clearly demonstrated that when the poor pharmacokinetic profile/short halflife of JHU 1057 was circumvented through continuous IV infusion, the enhanced D-serine plasma levels were sustained.

\section{Infusion of DAAO Inhibitors did not Increase D-serine Plasma Exposure in Monkeys}

Similar oral D-serine \pm DAAO inhibitor co-administration experiments were next performed in baboons. Given the mouse data showing the most prominent effects when the DAAO inhibitor was dosed IV, we chose to use chronic $24 \mathrm{~h}$ IV infusion of the three DAAO inhibitors in the baboons. In contrast to the data in mice, total D-serine exposures and D-serine elimination were largely unchanged with continuous IV infusion of the DAAO inhibitors CBIO (Figure 4a), JHU 1057 (Figure 4c), or JHU 1377 (Figure 4e). Plasma concentrations of each of the DAAO inhibitors remained constant for the duration of the IV infusion at $3-4 \mu \mathrm{M}$ for CBIO (Figure 4b), 2-3 $\mu \mathrm{M}$ for JHU 1057 (Figure 4d), and 5-6 $\mu \mathrm{M}$ for JHU 1377 (Figure 4f). Importantly, these concentrations exceeded their $\mathrm{K}_{i}$ values by $>60$-fold for the duration of the $24 \mathrm{~h}$ infusion. 
a

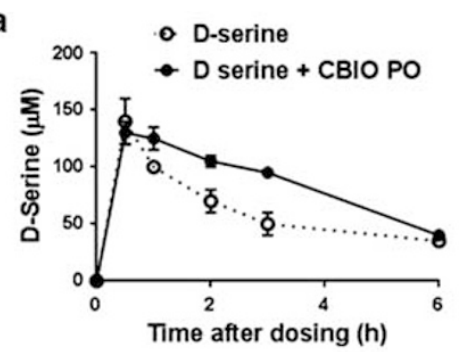

b

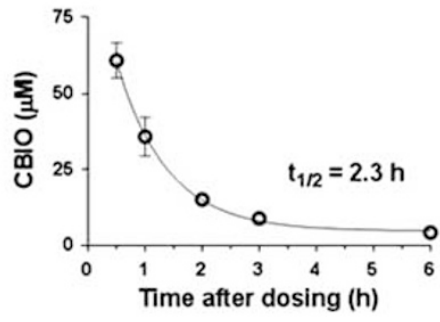

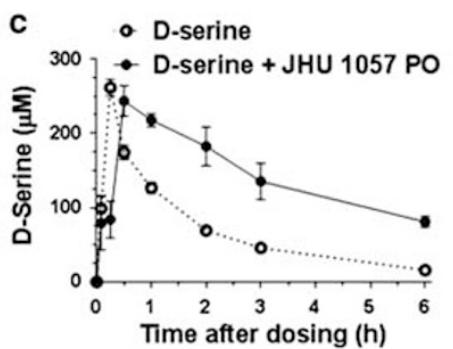

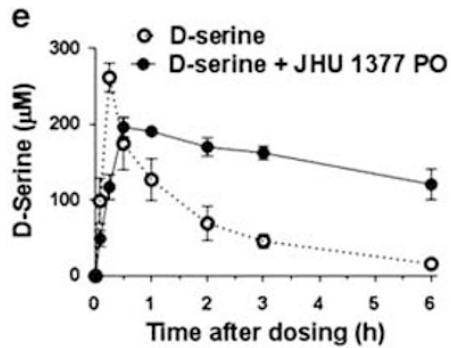

d

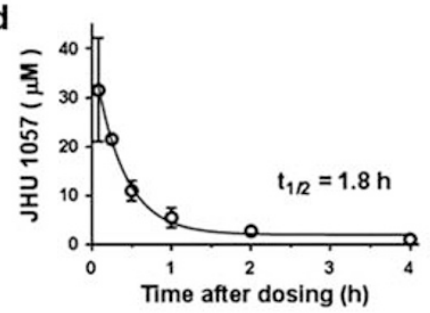

f

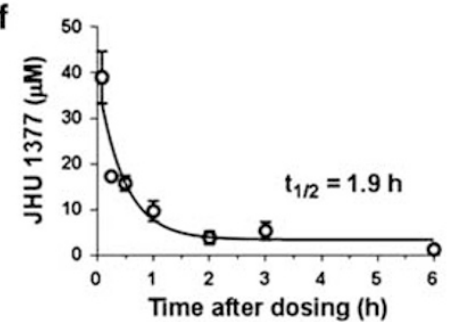

\begin{tabular}{|l|c|c|c|c|}
\hline $\mathrm{g}$ & $\begin{array}{c}\text { D-serine } \\
(30 \mathrm{mg} / \mathrm{kg} \mathrm{PO})\end{array}$ & $\begin{array}{c}\text { D-serine }+ \\
\mathrm{CBIO}(30 \mathrm{mg} / \mathrm{kg} \mathrm{PO})\end{array}$ & $\begin{array}{c}\text { D-serine }+ \\
\mathrm{JHU} 1057(100 \mathrm{mg} / \mathrm{kg} \mathrm{PO})\end{array}$ & $\begin{array}{c}\text { D-serine }+ \\
\mathrm{JHU} 1377(30 \mathrm{mg} / \mathrm{kg} \mathrm{PO})\end{array}$ \\
\hline $\mathrm{AUC}_{0.6 \mathrm{~h}}$ & $412 \pm 8$ & $514 \pm 3^{*}$ & $857 \pm 34^{*}$ & $922 \pm 34^{*}$ \\
\hline
\end{tabular}

Figure 2 Effect of oral single dose DAAO inhibitor on plasma concentrations of D-serine in mice-D-serine $\pm D A A O$ inhibitor were simultaneously administered to mice and plasma samples were collected at the times indicated. D-serine and DAAO inhibitor concentrations were determined by LC-MS. (a) D-serine plasma concentration following D-serine (30 mg/ $/ \mathrm{kg} \mathrm{PO}) \pm \mathrm{CBIO}$ (30 mg/kg PO), (b) CBIO plasma concentration following CBIO (30 mg/kg PO), (c) D-serine plasma concentration following D-serine (30 mg/kg PO) $\pm J H U$ I 057 (I 00 mg/kg PO), (d) JHU I 057 plasma concentration following JHU I 057 ( $100 \mathrm{mg} / \mathrm{kg} \mathrm{PO}$ ). (e) D-serine plasma concentration following D-serine (30 mg/kg PO) $\pm J H U$ I 377 (30 mg/kg). (f) JHU I 377 plasma concentration following $J H U I 377$ (30 mg/kg PO). Data for each time point is the average of values obtained from 3-5 mice. Error bars correspond to \pm SEM. AUC values (nmol h/ml) and terminal half-lives were calculated using the PK Functions for Microsoft Excel macro program (Methods). (g) AUC values for traces in (a, c, and e). $* Z_{\text {obs }}>1.96$ considered statistically significantly different versus D-serine alone.

\section{Infusion of JHU 1057 did not Increase D-serine Plasma Exposure in Dogs}

We next tested the co-administration paradigm in another large animal species. Beagle dogs were given oral D-serine \pm continuous IV JHU 1057 ( $3 \mathrm{mg} / \mathrm{kg}$ IV bolus followed by $3 \mathrm{mg} / \mathrm{kg} / \mathrm{h}$ infusion). Similar to the monkey data, D-serine exposure and elimination remained unaffected by JHU 1057 (Figure 5a). Similar results were obtained when a corresponding $10 \mathrm{mg} / \mathrm{kg} \mathrm{JHU} 1057$ regimen was used (Figure 5b). JHU 1057 plasma levels at 3 and $10 \mathrm{mg} / \mathrm{kg}$ regimens were $\sim 5$ and $20 \mu \mathrm{M}$, respectively (Figure $5 \mathrm{c}$ ), which is over 160- and 600 -fold its $K_{\mathrm{i}}$ value for DAAO inhibition $(30 \mathrm{nM})$.

\section{Extensive JHU 1057 PPB did not Explain Lack of Effect on D-serine Plasma Exposure in Baboon or Beagle Dog}

We next determined JHU 1057 PPB in mouse, baboon, and beagle dog to ensure that extensive PPB was not the reason for the compound's lack of effect on D-serine exposure. Using standard equilibrium dialysis methods (Acharya et al, 2006) JHU 1057 PPB was 18\% in mouse, $94 \%$ in baboon, and $69 \%$ in beagle dog. In monkey, the total concentration of JHU 1057 at equilibrium during IV infusion was $\sim 2 \mu \mathrm{M}$ (Figure $4 \mathrm{~d}$ ) so the concentration of JHU 1057 corresponding to $6 \%$ unbound was $\sim 120 \mathrm{nM}$ about fourfold its $K_{\mathrm{i}}$ value $(30 \mathrm{nM})$. Similarly, in dog the total concentration of JHU 1057 at equilibrium during IV infusion at $10 \mathrm{mg} / \mathrm{kg} / \mathrm{h}$ was $\sim 20 \mu \mathrm{M}$ (Figure $5 \mathrm{c}$ ) so the concentration of JHU 1057 corresponding to $31 \%$ unbound was $\sim 6.2 \mu \mathrm{M}$ $\sim 200$-fold the $K_{\mathrm{i}}$ value. In short, the fraction of unbound JHU 1057 circulating in plasma in both monkey and dog was in excess of the concentration needed to inhibit DAAO.

\section{DISCUSSION}

The most salient finding from the work we present here is the disparate results obtained in the IV infusion experiments using mice (Figure 3) vs those using monkeys (Figure 4) and dogs (Figure 5). When IV infusion of a DAAO inhibitor was used in mice D-serine levels were sustained with a complete loss of D-serine elimination (Figure 3) similar to results obtained with the DAAO KO mice (Rais et al, 2012). In stark contrast to the finding in the mouse, when similar IV infusions with three potent DAAO inhibitors, CBIO, JHU 1057, and JHU 1377, were used in monkeys, D-serine elimination was the same as in the absence of DAAO inhibitor (Figure 4). Same results were observed with JHU 1057 in dogs (Figure 5).

In mice, when CBIO, JHU 1057, and JHU 1377 were administered orally in combination with oral D-serine, they all showed increases in plasma D-serine levels (Figure 2a, c and e). The results with CBIO were similar to those 
¿ D-serine + JHU $1057 \mathrm{PO}$

- D-serine + JHU 1057 IV infusion

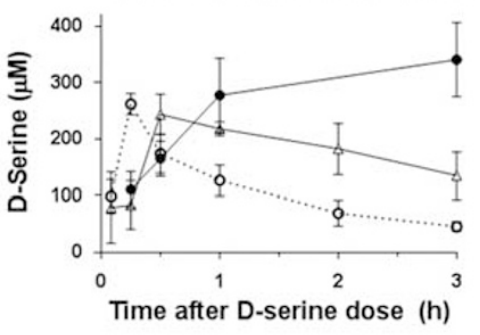

\begin{tabular}{|c|c|c|c|}
\hline b & $\begin{array}{c}\text { D-serine } \\
(30 \mathrm{mg} / \mathrm{kg} \mathrm{PO})\end{array}$ & $\begin{array}{c}\text { D-serine }+ \\
\text { JHU 1057(100 mg/kg PO })\end{array}$ & $\begin{array}{c}\text { D-serine + } \\
\text { JHU 1057 (1 mg/kg/h IV infusion })\end{array}$ \\
\hline AUC $_{0.3 \mathrm{~h}}$ & $319 \pm 3$ & $532 \pm 19^{\circ}$ & $776 \pm 41^{*}$ \\
\hline
\end{tabular}

Figure 3 Effect of IV infusion of JHU I 057 on plasma concentrations of D-serine in mice - (a) D-serine doses were $30 \mathrm{mg} / \mathrm{kg}$ PO in all cases. Plasma samples were collected at times indicated and analyzed for D-serine by LC-MS. Circles: D-serine concentration over time after D-serine administration. Squares: D-serine concentration over time after administration of D-serine and JHU 1057 ( I 00 mg/kg PO). Triangles: D-serine concentration over time after administration of D-serine and JHU 1057 (IV infusion I mg/ $/ \mathrm{kg} / \mathrm{h}$ ). Data for each time point is the average of values obtained from three mice. Error bars correspond to \pm S.E.M. (b) AUC values $(\mathrm{nmol} \mathrm{h} / \mathrm{mL})$ for traces in (a). ${ }^{*} Z_{\text {obs }}>1.96$ considered statistically significantly different versus D-serine alone.
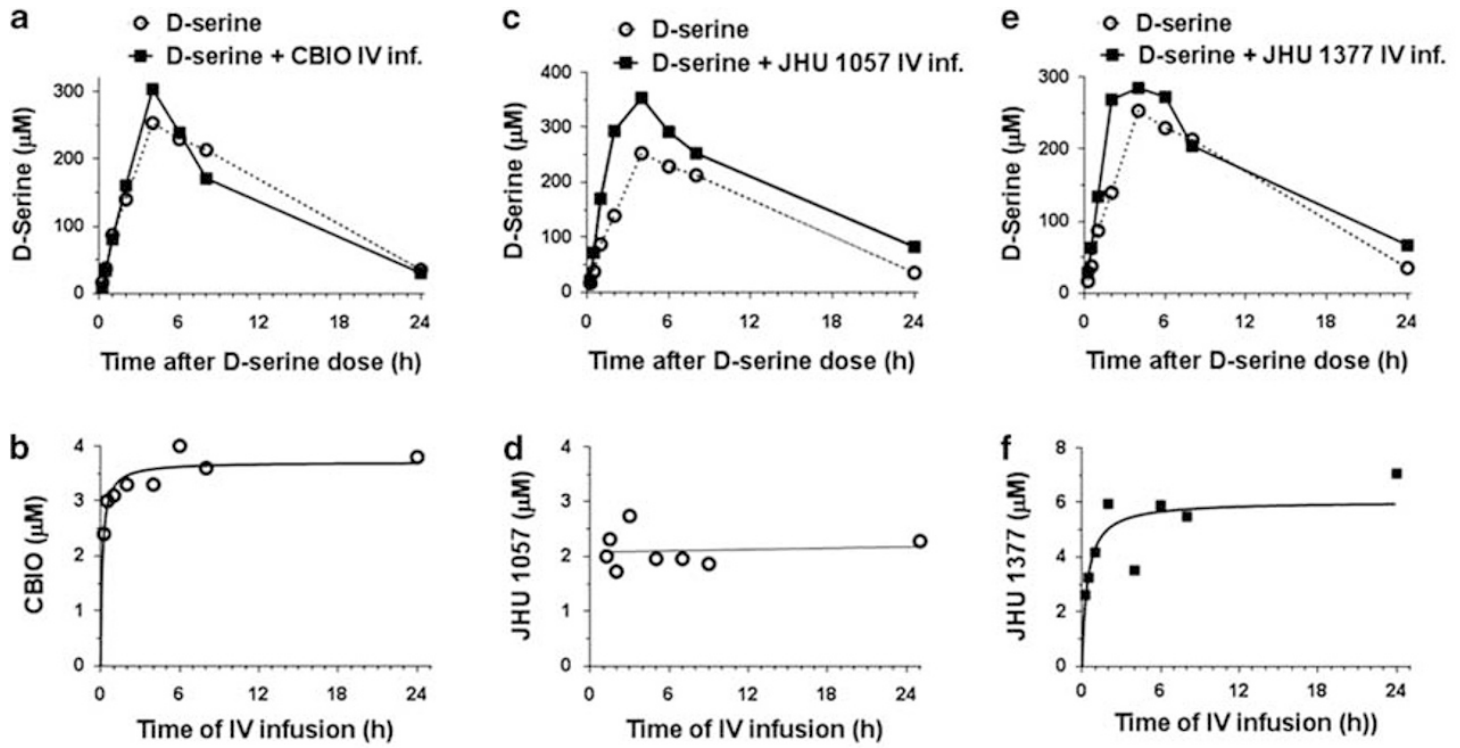

\begin{tabular}{|c|c|c|c|c|}
\hline $\mathbf{g}$ & D-serine & $\begin{array}{c}\text { D-serine }+ \\
\mathrm{CBIO}(0.1 \mathrm{mg} / \mathrm{kg} / \mathrm{h})\end{array}$ & $\begin{array}{c}\text { D-serine }+ \\
\mathrm{JHU} 1057(0.5 \mathrm{mg} / \mathrm{kg} / \mathrm{h})\end{array}$ & $\begin{array}{c}\text { D-serine }+ \\
\mathrm{JHU} 1377(0.5 \mathrm{mg} / \mathrm{kg} / \mathrm{h})\end{array}$ \\
\hline $\mathrm{AUC}_{0-24 \mathrm{~h}}$ & 3457 & 3181 & 4830 & 4022 \\
\hline
\end{tabular}

Figure 4 Effect of IV infusion of DAAO inhibitors on plasma concentrations of D-serine in baboons-Baboons were dosed with D-serine ( $30 \mathrm{mg} / \mathrm{kg}$ $\mathrm{PO}) \pm \mathrm{DAAO}$ inhibitors (IV infusion for $24 \mathrm{~h}$ ) and plasma samples were collected at 0.25, 0.5, I, 2, 4, 6, 8, and $24 \mathrm{~h}$ for analyses of both D-serine and DAAO inhibitor by LC-MS. (a) D-serine plasma concentration following D-serine+CBIO (0.I mg/kg/h IV infusion), (b) CBIO plasma concentration during CBIO IV infusion $(0.1 \mathrm{mg} / \mathrm{kg} / \mathrm{h})$, (c) D-serine plasma concentration following D-serine $\pm J H U 1057$ (0.5 mg/ $/ \mathrm{kg} / \mathrm{h} \mathrm{IV} \mathrm{infusion),} \mathrm{(d)} \mathrm{JHU} \mathrm{I} 057$ plasma concentration during $J H U$ I $057 \mathrm{IV}$ infusion $(0.5 \mathrm{mg} / \mathrm{kg} / \mathrm{h})$. (e) D-serine plasma concentration following D-serine $\pm J H U$ I 377 (0.5 mg/kg/h IV infusion). (f) JHU I 377 plasma concentration during JHU I 377 IV infusion $(0.5 \mathrm{mg} / \mathrm{kg} / \mathrm{h})$. (g) AUC values $(\mathrm{nmol} / \mathrm{h} / \mathrm{ml})$ for traces in (a, c, and e).

previously reported using rats (Ferraris et al, 2008) and the results with JHU 1057 and JHU 1377 confirmed and extended the observation to a structurally distinct chemical class. CBIO (Figure 1b) is a benzoisoxazole (Ferraris et al,
2008), whereas JHU 1057 (Figure 1c) and JHU 1377 (Figure 1d) incorporate the 6-hydroxy-1, 2, 4-triazine-3, 5 $(2 \mathrm{H}, 4 \mathrm{H})$-dione scaffold (Hin et al, 2015). Even though there was an increase in D-serine exposure in the presence of 
a

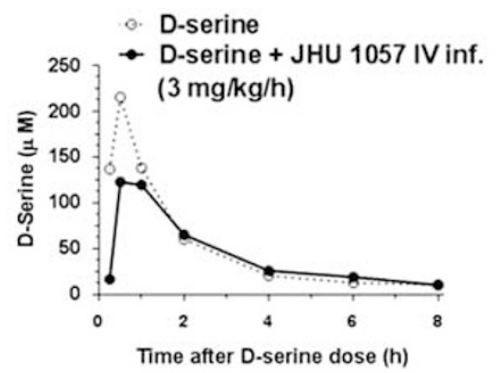

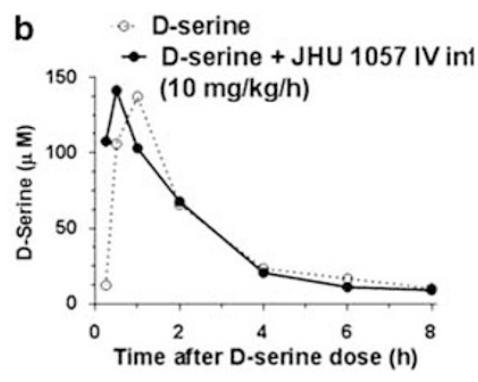

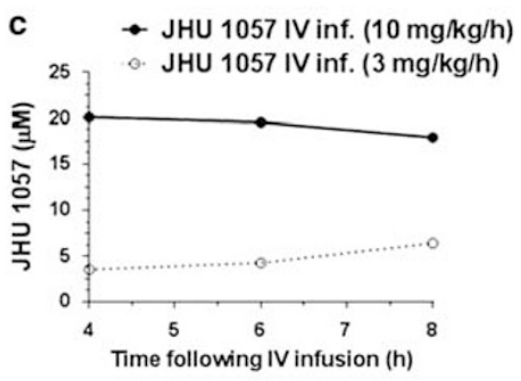

\begin{tabular}{|c|c|c|c|}
\hline d & D-serine & $\begin{array}{c}\text { D-serine }+ \\
\text { JHU } 1057(3 \mathrm{mg} / \mathrm{kg} / \mathrm{h})\end{array}$ & $\begin{array}{c}\text { D-serine }+ \\
\text { JHU } 1057(10 \mathrm{mg} / \mathrm{kg} / \mathrm{h})\end{array}$ \\
\hline AUC $_{0.8 \mathrm{~h}}$ & 387.3 & 338.9 & 331.9 \\
\hline $\mathrm{AUC}_{0.8 \mathrm{~h}}$ & 335.4 & & \\
\hline
\end{tabular}

Figure 5 Effect of IV JHU I 057 on plasma concentrations of D-serine in beagle dogs_Dogs were given D-serine $(10 \mathrm{mg} / \mathrm{kg} P O) \pm J H U$ I $057(3 \mathrm{or} I 0 \mathrm{mg} / \mathrm{kg}$ IV bolus followed by 3 or $10 \mathrm{mg} / \mathrm{kg} / \mathrm{h} \mathrm{IV}$ ) initiated $2 \mathrm{~h}$ post D-serine. Plasma samples were collected at 0.25, 0.5, I, 2, 4, 6, and $8 \mathrm{~h}$ after D-serine administration for analyses of both D-serine and JHU 1057 by LC-MS. (a) D-serine plasma concentration after D-serine+3 mg/kg JHU I 057; (b) D-serine plasma concentration after D-serine $+10 \mathrm{mg} / \mathrm{kg} \mathrm{JHU} \mathrm{I057;} \mathrm{(c)} \mathrm{JHU} 1057$ concentrations during 3 and $10 \mathrm{mg} / \mathrm{kg}$ regimens. Each experimental point corresponds to a single determination. (d) AUC values $(\mathrm{nmol} / \mathrm{h} / \mathrm{ml})$ for traces in (a and b).

DAAO inhibitors, the increase was not sustained. The limited effect was reasoned to be due to the short plasma terminal half-lives of the DAAO inhibitors, which were $2.3,1.8$, and $1.9 \mathrm{~h}$ for CBIO, JHU 1057, and 1377, respectively (Figure $2 \mathrm{~b}, \mathrm{~d}$ and $\mathrm{f}$ ). To circumvent the short terminal halflives, JHU 1057 was subsequently given as chronic IV infusion to enhance DAAO inhibitor plasma exposure over time (Figure 3). The results indicated that as long as DAAO inhibitor was present in plasma through IV infusion, enhanced plasma D-serine levels were sustained (Figure 3). These data support the critical role of DAAO in D-serine metabolism in mice. The results were consistent with data showing that when wild-type and transgenic mice lacking DAAO were given D-serine, the KO mice exhibited sustained D-serine levels in plasma $\left(t_{1 / 2}>10 \mathrm{~h}\right)$, whereas wild-type mice exhibited rapid D-serine elimination $\left(t_{1 / 2}=1.2 \mathrm{~h}\right)$ (Rais et al, 2012).

Because of our interest in the clinical translation of this therapy, we wanted to determine whether DAAO inhibitor-enhancement of D-serine exposure could also be confirmed in a species closer to humans: non-human primates. To that effect, we examined the effect of CBIO, JHU 1057, and JHU 1377 on D-serine exposure in baboons. Baboons were given $\mathrm{D}$-serine $(30 \mathrm{mg} / \mathrm{kg} \mathrm{PO}) \pm$ each of the three DAAO inhibitors as IV infusion to ensure adequate presence of inhibitor in plasma during the course of the study. To our surprise, unlike the rodent data, D-serine exposure in plasma was largely unaffected by the presence of a concomitant DAAO inhibitor (Figure 4a, c and e) even though the inhibitors reached plasma steady concentrations of $2-6 \mu \mathrm{M}$ (Figure $4 \mathrm{~b}, \mathrm{~d}$ and f), well above their $20-40 \mathrm{nM} \mathrm{K} K_{\mathrm{i}}$ values (Figure 2). Changes in AUC were 0.9, 1.4, and 1.1-fold for CBIO, JHU 1057, and JHU 1377, respectively (Figure 4g). Taken together, the results with the three inhibitors suggest differences in AUC were within experimental error.

As these effects in baboons were unexpected, we next chose to study this co-administration strategy in beagle dogs. Similar to the monkeys, however, we found that D-serine exposure in dogs was completely unaffected by continuous IV DAAO inhibitor infusion (Figure $5 a$ and $b$ ), even though inhibitor levels were well above its $K_{\mathrm{i}}$ value (Figure 5c).

Even though the steady state concentrations of DAAO inhibitors in monkey and dog plasma were 60-600-fold times the $K_{\mathrm{i}}$, we next reasoned that if the compounds were extensively protein bound, it could have confounded the results. However, when protein binding was considered for JHU 1057, the free fraction in plasma still exceeded the DAAO $K_{\mathrm{i}}$ by fourfold in monkey and 200-fold in dog, suggesting that the lack of effect of DAAO inhibitors was likely not due to the inhibitors bound to plasma proteins.

The DAAO inhibitors used in these studies were expected to inhibit peripheral DAAO only, because they do not cross the blood brain barrier. If peripheral inhibition of DAAO in monkey or dog had had an effect, it would have resulted in increased D-serine levels in plasma and increased D-serine transport into brain. This hypothesis has been confirmed in 
previous studies with rodents where increased plasma $\mathrm{D}$-serine resulted in increased brain $\mathrm{D}$-serine measured via micro dialysis (Ferraris et al, 2008; Hashimoto et al, 2009). As in our studies plasma D-serine levels did not increase in monkey and dog, brain D-serine levels were not expected to increase either.

The reason for the difference in the effect of DAAO inhibition on D-serine levels among species is not clear. Differential DAAO inhibition across species is unlikely: CBIO, JHU 1057, and JHU 1377 were all shown to be potent inhibitors of human DAAO (Figure 1) and also increased D-serine plasma levels in mice (Figure 2), indicating broad DAAO inhibition. There is also high-sequence identity of DAAO across species; mouse, dog, and monkey exhibit $80.7 \%, 83.3 \%$, and $94.2 \%$ sequence identity with human DAAO, respectively (http://www.uniprot.org). Most important, the DAAO amino-acid residues expected to interact with these inhibitors at the active site (Tyr 228, Arg 283, and Tyr 224) (Ferraris et al, 2008) are conserved across these species.

Oral D-serine disposition is different between rodents and baboons. As has been previously reported (Ferraris et al, 2008; Rais et al, 2012), we found that D-serine absorption in mice is fast reaching maximum concentration in $<1 \mathrm{~h}$ followed by rapid elimination (Figure $2 \mathrm{a}, \mathrm{c}$ and $\mathrm{e}$ ). D-serine absorption in baboons, however, was found to be considerably slower, reaching maximum concentration at $\sim 4 \mathrm{~h}$ followed by relatively slower elimination (Figure $4 a, c$ and e). D-serine disposition in dogs was rapid and similar to mice (Figure 5a and $b$ ) yet DAAO inhibition did not have an effect on D-serine exposure in dogs. Therefore, D-serine disposition alone cannot account for the contrasting DAAO inhibitor effects.

Differences in D-serine metabolism among species are one possible reason for the differential effect of DAAO inhibitors on D-serine exposure. Administration of $\mathrm{D}$-serine to rats causes nephrotoxicity (Carone et al, 1985; Ganote et al, 1974; Kaltenbach et al, 1979; Morehead et al, 1946) resulting from DAAO-catalyzed D-serine oxidation (Maekawa et al, 2005), whereas administration of D-serine to humans even at concentrations of $120 \mathrm{mg} / \mathrm{kg}$ had no major safety issues (Kantrowitz et al, 2010), suggesting D-serine metabolism across species may not be the same. In line with these findings, a species comparison of basal urinary $\mathrm{D}$-serine concentrations showed much higher levels of D-serine in human and dog urine vs rats and mice (Huang et al, 1998; Miyoshi et al, 2009), suggesting that D-serine in human and dog may be preferentially excreted by the kidneys versus metabolized by DAAO. If true, then DAAO inhibition would be reasoned to have less effect on plasma D-serine levels in these species, similar to our findings in monkeys and dogs, and different to our and others' findings in rodents. Even though alternate pathways to D-serine metabolism in addition to DAAO oxidation cannot be ruled out, the relatively high concentrations of $\mathrm{D}$-serine in human and dog urine compared with rat would suggest that in these species $\mathrm{D}$-serine excretion is a significant $\mathrm{D}$-serine elimination route. Different roles for DAAO across species are also suggested by the observation that DAAO is a flavoprotein where interactions with the flavin adenine dinucleotide (FAD) coenzyme are closely modulated to catalyze a variety of oxidation/reduction processes with different catalytic efficiencies. Pertinent to this point is the finding that the binding affinity of FAD for human DAAO is 400 -fold weaker than for fungi DAAO (Rhinotyphlops gracilis) and 36-fold weaker than for porcine DAAO (Pollegioni et al, 2007). Human DAAO can catalyze D-serine oxidation in vitro in the presence of sufficient FAD but it may have lower activity under physiological conditions if much less FAD is available. DAAO can also catalyze many other oxidation reactions (Kawazoe et al, 2007b). In this regard, kinetic data show that the maximum velocity of catalysis of D-DOPA oxidation is much greater than that for $\mathrm{D}$-serine, suggesting $\mathrm{DAAO}$ involvement in alternative pathways of dopamine biosynthesis (Kawazoe et al, 2007a,b). Different roles for DAAO across species are also suggested by differences in expression patterns. For example, humans express DAAO in both the liver and the kidney while mice express DAAO in the kidney but not the liver (Tishkov and Khoronenkova, 2005).

Our results were unexpected in light of a recent clinical study showing that the purported DAAO inhibitor benzoate $\left(\mathrm{IC}_{50}=16 \mu \mathrm{M}\right)$ (Vanoni et al, 1997) improved a variety of symptom domains and neurocognition in patients with schizophrenia when used as add-on treatment (Lane et al, 2013). Unfortunately, the ability of benzoate to inhibit $\mathrm{DAAO}$ and/or alter D-serine plasma or CNS levels were not explored in this study. In a separate PK study when benzoate was given to humans at $40 \mathrm{mg} / \mathrm{kg}$ ( $2.8 \mathrm{~g}$ for a $70 \mathrm{~kg}$ person) DAAO inhibitory concentrations of benzoate in plasma were reached only for $3 \mathrm{~h}$. Further, apparent volume of distribution $\left(V_{\mathrm{d}}\right)$ of benzoate was $0.248 \mathrm{l} / \mathrm{kg}$, suggesting that its exposure to the liver and kidney are likely less than in the bloodstream (Kubota and Ishizaki, 1991). In the efficacy study mentioned above benzoate dose was about one-third of the dose used in the PK study ( $1 \mathrm{~g} /$ day) so benzoate exposure would have been even less. CBIO, an 80 -fold more potent benzoate analog (Ferraris et al, 2008), did not have an effect on D-serine plasma levels in the monkey, even when the compound was given as an IV infusion for $24 \mathrm{~h}$ to ensure DAAO inhibition at all times. Taken together, the above considerations suggest the beneficial effects observed with benzoate are likely due to a pharmacological mechanism other than DAAO inhibition.

In contrast to behavioral studies in rodent models of psychiatric disease where the effects across species can be hard to confirm, biomarker studies evaluating drug-induced changes in analytes found in biological fluids (eg, plasma, CSF, urine) can be more readily confirmed across species including dogs, primates, and eventually in clinical studies. Importantly, in larger laboratory animal species such biomarker studies can also be conducted without major discomfort or sacrificing of the animals.

In summary, the work presented here shows that in contrast to rodents, exposure of exogenously administered $\mathrm{D}$-serine cannot be increased in baboons or beagle dogs by DAAO inhibition, suggesting that DAAO is not critically involved in peripheral D-serine metabolism in these species. This work underlines the usefulness of using several species for a more informed expectation of drug action and provides caution regarding the utility of the D-serine/DAAO inhibition strategy for patients with schizophrenia.

\section{FUNDING AND DISCLOSURE}

The authors declare no conflict of interest. 


\section{ACKNOWLEDGMENTS}

This work was supported by National Institutes of Health (R01MH091387 to TT) and the Johns Hopkins Brain Science Institute.

\section{REFERENCES}

Acharya MR, Sparreboom A, Sausville EA, Conley BA, Doroshow JH, Venitz J et al (2006). Interspecies differences in plasma protein binding of MS-275, a novel histone deacetylase inhibitor. Cancer Chemother Pharmacol 57: 275-281.

Adage T, Trillat AC, Quattropani A, Perrin D, Cavarec L, Shaw J et al (2008). In vitro and in vivo pharmacological profile of AS057278, a selective d-amino acid oxidase inhibitor with potential anti-psychotic properties. Eur Neuropsychopharmacol 18: $200-214$.

Ator NA (2000). Zaleplon and triazolam: drug discrimination, plasma levels, and self-administration in baboons. Drug Alcohol Depend 61: 55-68.

Bailer AJ (1988). Testing for the equality of area under the curves when using destructive measurement techniques. J Pharmacokinet Biopharm 16: 303-309.

Berna MJ, Ackermann BL (2007). Quantification of serine enantiomers in rat brain microdialysate using Marfey's reagent and LC/MS/MS. J Chromatogr B Analyt Technol Biomed Life Sci 846: 359-363.

Carone FA, Nakamura S, Goldman B (1985). Urinary loss of glucose, phosphate, and protein by diffusion into proximal straight tubules injured by $\mathrm{D}$-serine and maleic acid. Lab Invest 52: 605-610.

Cheng Y, Prusoff WH (1973). Relationship between the inhibition constant (K1) and the concentration of inhibitor which causes 50 per cent inhibition (I50) of an enzymatic reaction. Biochem Pharmacol 22: 3099-3108.

Chung SP, Sogabe K, Park HK, Song Y, Ono K, Abou El-Magd RM et al (2010). Potential cytotoxic effect of hydroxypyruvate produced from $\mathrm{D}$-serine by astroglial $\mathrm{D}$-amino acid oxidase. J Biochem 148: 743-753.

Cook SP, Galve-Roperh I, Martinez del Pozo A, Rodriguez-Crespo I (2002). Direct calcium binding results in activation of brain serine racemase. J Biol Chem 277: 27782-27792.

Coyle JT (2006). Glutamate and schizophrenia: beyond the dopamine hypothesis. Cell Mol Neurobiol 26: 365-384.

Dixon M, Kleppe K (1965). D-Amino acid oxidase II. Specificity, competitive inhibition and reaction sequence. Biochimica et Biophysica Acta 96: 368-382.

Duplantier AJ, Becker SL, Bohanon MJ, Borzilleri KA, Chrunyk BA, Downs JT et al (2009). Discovery, SAR, and pharmacokinetics of a novel 3-hydroxyquinolin-2(1H)-one series of potent D-amino acid oxidase (DAAO) inhibitors. J Med Chem 52: 3576-3585.

Ferraris D, Duvall B, Ko YS, Thomas AG, Rojas C, Majer P et al (2008). Synthesis and biological evaluation of D-amino acid oxidase inhibitors. J Med Chem 51: 3357-3359.

Ferraris DV, Tsukamoto T (2011). Recent advances in the discovery of D-amino acid oxidase inhibitors and their therapeutic utility in schizophrenia. Curr Pharm Des 17: 103-111.

Ganote CE, Peterson DR, Carone FA (1974). The nature of D-serine-induced nephrotoxicity. Am J Pathol 77: 269-282.

Hashimoto K, Fujita Y, Horio M, Kunitachi S, Iyo M, Ferraris D et al (2009). Co-administration of a D-amino acid oxidase inhibitor potentiates the efficacy of D-serine in attenuating prepulse inhibition deficits after administration of dizocilpine. Biol Psychiatry 65: 1103-1106.

Heresco-Levy U, Javitt DC, Ebstein R, Vass A, Lichtenberg P, Bar G et al (2005). D-serine efficacy as add-on pharmacotherapy to risperidone and olanzapine for treatment-refractory schizophrenia. Biol Psychiatry 57: 577-585.

Hin N, Duvall B, Ferraris D, Alt J, Thomas AG, Rais R et al (2015). 6-Hydroxy-1,2,4-triazine-3,5(2H,4H)-dione derivatives as novel d-amino acid oxidase Inhibitors. J Med Chem 58: 7258-7272.

Huang Y, Nishikawa T, Satoh K, Iwata T, Fukushima T, Santa T et al (1998). Urinary excretion of D-serine in human: comparison of different ages and species. Biol Pharm Bull 21: 156-162.

Iwasa S, Tabara H, Song Z, Nakabayashi M, Yokoyama Y, Fukushima T (2011). Inhibition of D-amino acid oxidase activity by antipsychotic drugs evaluated by a fluorometric assay using D-kynurenine as substrate. Yakugaku Zasshi 131: 1111-1116.

Javitt DC, Silipo G, Cienfuegos A, Shelley AM, Bark N, Park M et al (2001). Adjunctive high-dose glycine in the treatment of schizophrenia. Int J Neuropsychopharmacol 4: 385-391.

Kaltenbach JP, Ganote CE, Carone FA (1979). Renal tubular necrosis induced by compounds structurally related to D-serine. Exp Mol Pathol 30: 209-214.

Kantrowitz JT, Malhotra AK, Cornblatt B, Silipo G, Balla A, Suckow RF et al (2010). High dose D-serine in the treatment of schizophrenia. Schizophr Res 121: 125-130.

Kawazoe T, Park HK, Iwana S, Tsuge H, Fukui K (2007a). Human D-amino acid oxidase: an update and review. Chem Rec 7: 305-315.

Kawazoe T, Tsuge H, Imagawa T, Aki K, Kuramitsu S, Fukui K (2007b). Structural basis of D-DOPA oxidation by D-amino acid oxidase: alternative pathway for dopamine biosynthesis. Biochem Biophys Res Commun 355: 385-391.

Kubota K, Ishizaki T (1991). Dose-dependent pharmacokinetics of benzoic acid following oral administration of sodium benzoate to humans. Eur J Clin Pharmacol 41: 363-368.

Lane HY, Chang YC, Liu YC, Chiu CC, Tsai GE (2005). Sarcosine or D-serine add-on treatment for acute exacerbation of schizophrenia: a randomized, double-blind, placebo-controlled study. Arch Gen Psychiatry 62: 1196-1204.

Lane HY, Lin CH, Green MF, Hellemann G, Huang CC, Chen PW et al (2013). Add-on treatment of benzoate for schizophrenia: a randomized, double-blind, placebo-controlled trial of D-amino acid oxidase inhibitor. JAMA Psychiatry 70: 1267-1275.

Lane HY, Lin CH, Huang YJ, Liao CH, Chang YC, Tsai GE (2010). A randomized, double-blind, placebo-controlled comparison study of sarcosine (N-methylglycine) and D-serine add-on treatment for schizophrenia. Int $J$ Neuropsychopharmacol 13: 451-460.

Lukas SE, Griffiths RR, Bradford LD, Brady JV, Daley L (1982). A tethering system for intravenous and intragastric drug administration in the baboon. Pharmacol Biochem Behav 17: 823-829.

Maekawa M, Okamura T, Kasai N, Hori Y, Summer KH, Konno R (2005). D-amino-acid oxidase is involved in D-serine-induced nephrotoxicity. Chem Res Toxicol 18: 1678-1682.

Malhotra AK, Pinals DA, Adler CM, Elman I, Clifton A, Pickar D et al (1997). Ketamine-induced exacerbation of psychotic symptoms and cognitive impairment in neuroleptic-free schizophrenics. Neuropsychopharmacology 17: 141-150.

Malhotra AK, Pinals DA, Weingartner H, Sirocco K, Missar CD, Pickar D et al (1996). NMDA receptor function and human cognition: the effects of ketamine in healthy volunteers. Neuropsychopharmacology 14: 301-307.

Miyoshi Y, Hamase K, Tojo Y, Mita M, Konno R, Zaitsu K (2009). Determination of $\mathrm{D}$-serine and $\mathrm{D}$-alanine in the tissues and physiological fluids of mice with various $\mathrm{D}$-amino-acid oxidase activities using two-dimensional high-performance liquid chromatography with fluorescence detection. J Chromatogr B Analyt Technol Biomed Life Sci 877: 2506-2512. 
Molla G, Sacchi S, Bernasconi M, Pilone MS, Fukui K, Polegioni L (2006). Characterization of human D-amino acid oxidase. FEBS Lett 580: 2358-2364.

Morehead RP, Poe WD et al (1946). The influence of age and species on the nephrotoxic action of d1-serine. Am J Pathol 22: 658.

Mothet JP, Parent AT, Wolosker H, Brady RO Jr, Linden DJ, Ferris CD et al (2000). D-serine is an endogenous ligand for the glycine site of the N-methyl-D-aspartate receptor. Proc Natl Acad Sci USA 97: 4926-4931.

Nutt JG, Woodward WR, Anderson JL (1985). The effect of carbidopa on the pharmacokinetics of intravenously administered levodopa: the mechanism of action in the treatment of parkinsonism. Ann Neurol 18: 537-543.

Ogaya T, Song Z, Ishii K, Fukushima T (2010). Changes in extracellular kynurenic acid concentrations in rat prefrontal cortex after D-kynurenine infusion: an in vivo microdialysis study. Neurochem Res 35: 559-563.

Oldendorf WH (1971). Brain uptake of radiolabeled amino acids, amines, and hexoses after arterial injection. Am J Physiol 221: 1629-1639.

Pollegioni L, Piubelli L, Sacchi S, Pilone MS, Molla G (2007). Physiological functions of D-amino acid oxidases: from yeast to humans. Cell Mol Life Sci 64: 1373-1394.

Rais R, Thomas AG, Wozniak K, Wu Y, Jaaro-Peled H, Sawa A et al (2012). Pharmacokinetics of oral D-serine in D-amino acid oxidase knockout mice. Drug Metab Dispos 40: 2067-2073.

Sacchi S, Bernasconi M, Martineau M, Mothet JP, Ruzzene M, Pilone MS et al (2008). pLG72 modulates intracellular D-serine levels through its interaction with D-amino acid oxidase: effect on schizophrenia susceptibility. J Biol Chem 283: 22244-22256.

Smith SM, Uslaner JM, Hutson PH (2010). The therapeutic potential of D-amino acid oxidase (DAAO) inhibitors. Open Med Chem J 4: 3-9.
Smith SM, Uslaner JM, Yao L, Mullins CM, Surles NO, Huszar SL et al (2009). The behavioral and neurochemical effects of a novel D-amino acid oxidase inhibitor compound 8 [4H-thieno [3,2-b] pyrrole-5-carboxylic acid] and D-serine. J Pharmacol Exp Ther 328: 921-930.

Tishkov VI, Khoronenkova SV (2005). D-Amino acid oxidase: structure, catalytic mechanism, and practical application. Biochemistry (Mosc) 70: 40-54.

Tsai G, Yang P, Chung LC, Lange N, Coyle JT (1998). D-serine added to antipsychotics for the treatment of schizophrenia. Biol Psychiatry 44: 1081-1089.

Tsai GE, Yang P, Chung LC, Tsai IC, Tsai CW, Coyle JT (1999). D-serine added to clozapine for the treatment of schizophrenia. Am J Psychiatry 156: 1822-1825.

Vanoni MA, Cosma A, Mazzeo D, Mattevi A, Todone F, Curti B (1997). Limited proteolysis and X-ray crystallography reveal the origin of substrate specificity and of the rate-limiting product release during oxidation of $\mathrm{D}$-amino acids catalyzed by mammalian D-amino acid oxidase. Biochemistry 36: 5624-5632.

Verrall L, Walker M, Rawlings N, Benzel I, Kew JN, Harrison PJ et al (2007). d-Amino acid oxidase and serine racemase in human brain: normal distribution and altered expression in schizophrenia. Eur J Neurosci 26: 1657-1669.

Weiser M, Heresco-Levy $U$, Davidson $M$, Javitt DC, Werbeloff N, Gershon AA et al (2012). A multicenter, add-on randomized controlled trial of low-dose d-serine for negative and cognitive symptoms of schizophrenia. J Clin Psychiatry 73: e728-e734.

Williams RE, Lock EA (2005). Sodium benzoate attenuates D-serine induced nephrotoxicity in the rat. Toxicology 207: 35-48.

Yang CR, Svensson KA (2008). Allosteric modulation of NMDA receptor via elevation of brain glycine and D-serine: the therapeutic potentials for schizophrenia. Pharmacol Ther 120: 317-332. 